\title{
POSTOPERATIVE TREATMENT WITH ARTIFICIAL RESPIRATION OF TWO THORACIC SURGICAL PATIENTS ${ }^{1}$
}

\author{
J. G. RoBson, F.F.A.R.C S.(ENG.) $)^{2}$
}

THE USE OF artificial respiration in the postoperative period for tuberculous patients was reported on by Bjork and Engstrom (1). When acute infection occurred in the only functioning lung of two of their patients, they maintained artuficial respiration for six and nine days, and both patients recovered.

The following report may be of interest to anaesthetists because of the growing use of such methods and it illustrates the application of prolonged artificial and assisted respiration without the necessity for complicated biochemical control.

The first patient was a woman of 46 with a long history of pulmonary tuberculosis In 1939 she had a seven-nb thoracoplasty for closure of a right apical cavity Closure was not complete and her sputum intermittently contained tubercle bacill thereafter. Fourteen years later (1953) a lesion develo jed on the left side which was controlled by chemotherapy. When this had hea-ed, in 1956, it was decided to remove the right lung to prevent re-infection.

Pneumonectomy proved to be very difficult. The bony chest wall was composed of plaques of regenerated bone, much of which had to be removed in order to mobjlize the lung. Closure of the chest was necessarily inefficient,

The postoperative course was stormy. With the very deficient chest wall, mediastunal movement was gross and coughing was mechanically almost impossible. She had attacks of great respuratory distress caused by the accumulation of secretions, but by the fourth day she was fairly well. During this period she was febrile. On the tenth day her condition rapidly deteriorated. The respiratory rate increased to between 40 and 50 per minute, she again had fever and she was at times disorientated. By the eleventh day she was comatose, flushed, cyanosed and sweating and obviously had marked carbon dioxide retention with anoxid The arterial oxygen saturation was 65 per cent, carbon dioxide content 97 vol. per cent (arterial blood) and the blood $\mathrm{Ph}$ was 7.3 Chest X-ray showed that there was patchy consolidation in the mid-zone of the remaining lung and that the heart had moved over to the left. The pulmonary infection following mechanical inefficiency of respiration had precipitated respiratory failure

Durmg tiansit to the operating theatre respiration ceased and orotracheal untubatıon was performed whlle she was makıng only an occasional anoxic gasp. She recovered consciousness after some thirty minutes of hyperventilation with oxygen. Four hours later, when her general condition had improved sufficiently, tracheostomy was performed under light cyclopropane anaesthesia. A cuffed cut-down Magill rubber tube no. 9 was inserted into the stoma and intermittent positive/negative pressure respiration was continued with a respirator.

1Presented at the Annual Meetung, Canadian Anaesthetasts' Society, Mont Tremblant, P Q June 20-22, 1956.

2Wellcome Research Department of Anaesthesia, McGill Unversity, Montreal, P.Q 
The respirator used was one described by Horton, Inkster and Pask (2). This machine is a pressure cycling device which provides ositive and negative phases and has a patient-controlled demand valve which a lows the delivery of gas to the pre-set pressure of the exertion of about $1 \mathrm{~cm}$. water negative pressure by the patient. The machıne was at first supplied through an entraining device from oxygen cylnders, the gas mixture containing about 50 per cent oxygen. With this mixture a pressure differential of $35 \mathrm{~cm}$. water, 25 positive, 10 negative, at a cycling rate of 40 per minute was required, in order to keep the patient a reasonable colour Gas exchange was so poor that the functioning lung had to be worked to this extreme degree. Such pressures would not have been required had pure oxygen been used, but the attainment of a reasonably high minute volume for the clearance of carbon dioxide was of major importance.

Within a few hours the chest wall on the right had become convex and showed little movement and the heart had moved over to the right. By the second day the arterial blood oxygen saturation was 96 per cent, carbon dioxide tension $40 \mathrm{~mm}$ mercury, carbon dioxide content 73 vol. per hundred and $\mathrm{Ph} 75$. Her respiratory rate had by this time been reduced to $20-22$ per minute and the negative phase was therefore discontinued. Respiratory control was from then on fairly simple. The positive pressure, and so the tidal volume, were reduced progressively until spontaneous respiration returned and the cycling rate was adjusted until it equalled the patient-triggered rate. The pressure was then slowly increased until apnoea once more just supervened. This process was carried out twice a day and it avoided the necessity for repeated blood gas estimations. This patient was very sensitive to the oxygen content of the supplied mixture and would not tolerate artificial respiration with air alone until the eighth day. On the same day a fall in temperature and pulse rate indicated resolution of the pulmonary infection. $\mathrm{X}$-ray at this time showed the left lung to be clear of infection and the heart in the normal position The efficient removal of secretions and the prevention of pulmonary collapse were of vital importance and a conscientious regimen of posturing with chest percussion and tracheo-bronchial aspiration was followed Secretions were kept flurd and easy to aspirate by efficient humidification of the gases. The patient's feelng of well-being, the pulse rate and blood pressure, reflected the efficiency with which this routine was carried out The cuff of the tracheal tube was deflated for one minute every two hours and no symptoms of tracheal pressure developed The tube did not require to be changed during the treatment

By the twenty-eighth day, the chest wall had become ngid enough for the artificial respiration to be discontinued. "Weaning" presented no difficulties. The tracheostome healed normally and the patient left the hospital well.

The second patient was a man of 56 with a history of pulmonary tuberculosis for two years On admission he had a complete tuberculous excavation of his right upper lobe. In December, 1955, the right upper lobe and the apical segment of the lower lobe were resected, this being technically very difficult. During a difficult convalescence he developed an empyema with a broncho-pleural fistula and this was drained.

In February, 1956, an upper four-rib thoracoplasty was performed as the 
closure of the fistula seemed to offer the only chance for his survival. Postoperatively he required repeated bronchoscopy as he was unable to cough effectively. The subscapular space, being in communication with the empyema space, became infected. His general condition progressively deteriorated and on the third postoperative day he presented a picture of gross carbon dioxide retention and anoxia. He was intubated without further anaesthesia, much pus was aspirated from his brcnchial. tree and he was artificially ventilated with the respirator. Within six hours he had improved so markedly that it seemed to be worthwhile to persist with artificial respiration and a tracheostomy was performed. Acclimatisation to the machine was very easy as this patient much appreciated the value of the sparing of his own efforts.

In the course of the next three weeks he nearly drowned many times as pus from the subscapular and empyema spaces flooded into his bronchi. The respirator was adjusted as described earlier and from time to time it was discontinued for short periods During these spells of spontaneous respiration his condition became worse despite continued removal of secretions. General nursing was very difficult as he was so emaciated. His wound broke down despite minute care With good metabolic supervision and repeated blood transfusion, his condition improved sufficiently for artificial respiration to be discontinued on the twenty-first postoperative day. A plugged tracheostomy tube was kept in place for the next two weeks to allow aspiration of his secretions. He died at this time from a coronary thrombosis, a large myocardial infarct of recent origin being demonstrated at autopsy.

\section{DisCUSSION}

Bjork and Engstrom note that in patients with a very low respiratory reserve, when acute infection develops in the functioning, lung, marked increases in the rate of ressiration above normal are required anc the pressure differential sometimes neecs to be high. This was the case with the first Jatient.

A tracheostomy alone will reduce the dead space by a sout $100 \mathrm{cc}$. and this of itself may be sufficient to allow effective carbon dioxide clearance in some patients. In the first patient it was quite obvious that the best chance of her survival lay in the encouragement of fixation of the chest wall and intermittent positive pressure respiration was the method of choice. The second patient was physically too weak either to cough up his secretions, or to breathe efficiently even through a tracheostomy, for the first three weeks after the institution of artficial respiration, so that decision was not difficult.

When any doubt exists about the employment of artificial respi-ation, the therapeutic test of oral intubation and manual artificial ventilation is tue obvious way to reach a decision.

\section{SUMMARY}

This paper describes the prolonged treatment by intermittent positive pressure respiration through a tracheostomy of two patients who developed respiratory failure following operation. 
One patient had a seven-rib thoracoplasty on the right side and, because of subsequent infection of her left lung from the incompletely closed cavity under the thoracoplasty, had a right pneumonectomy Following this the right chest wall was completely lax so that respiration and coughing were inefficient. Acute infection developed in the lung and respiratory fallure followed. Treatment was by artificial respuration for twenty-eight days through a tracheostomy using an intermittent positıve-negative pressure respirator which had a patient demand valve. The chest wall became firm and recovery followed.

The second patient developed a broncho-pleural fistula following right upper lobectomy for a tuberculous excavation of the right upper lobe. This was treated by thoracoplasty Respiratory fallure followed and he was treated by intermittent positive pressure respiration for twenty-one days He died twenty-one days later from myocardial infarction.

\section{Résumé}

Dans cet artıcle, nous faisons l'exposé du trattement prolongé de deux malades qui, à la suite d'une opération, ont fait un arrèt respiratorre et, après trachéotomie, ont été soumis à une respiration artificielle à pression positive intermittente

Le premier de ces malades avart subi une thoracoplastie drotte de sept côtes et, à cause d'une infection subséquente de son poumon gauche par la cavité droite incomplètement fermée par la thoracoplastie, a dû subir une pneumonectomie droite. Après ces opératıons, la paroı thoracique droıte éta1t complètement flasque de sorte que la respiration et la toux étaient insuffisantes Le poumon restant s'est infecté et la respiration a cessé. Le traitement a consısté en une respiration artuficielle durant 28 jours et cela par la trachéotomie On s'est servi d'un respurateur à pression positıve et négatıve intermittente qui était muni d'une valve à demande. La paro1 thoracique s'est solidifiée et la guérıson a suivi.

Le deuxième malade a fait une fistule bronchopleurale à la suite d'une lobectomie supérneure droite pour une cavité tuberculeuse du lobe supérieur droit Le traitement a consisté en thoracoplastie L' arrêt respiratorre est survenu et il a été traité, durant 21 jours, par une respiration artaficielle à pression positive intermittente Il mourut d'un infarctus du myocarde 21 jours plus tard

\section{ACKNOWLEDGMENTS}

My thanks are due to Mr Andrew Logan and Mr. David Wade of the Regional Thoracic Surgical Service, South Eastern Scotland Regıon, whose patients these were, for their enlightened attitude to the role of the anaesthetssts who are their colleagues

\section{REFERENCES}

1 Bjonk, O V, \& Engstrom, C G The Treatment of Ventilatory Insufficiency after Pulmonary Resection with Tracheostomy and Prolonged Artuficial Ventulation J Thoracic Surg 30.356 (1955)

2 Horton, J A G, Inkster, J S, \& Pask, E A Two More Respirators Brit J Anaesth $28170(1956)$ 